\title{
Occlusal tooth wear in human sculls of antique period from Vendenis and Municipium Dardanorum DD, Kosovo
}

\author{
Ferit Koçani ${ }^{1}$, Blerim Kamberi ${ }^{1}$, Jahja Dranqolli ${ }^{2}$, Kemal Luci ${ }^{3}$, Fatmir Peja ${ }^{3}$, Edmond Dragusha ${ }^{1}$, \\ Metush Disha $^{4}$ \\ ${ }^{1}$ Dental Pathology \& Endodontics, University of Prishtina, Faculty of Medicine/Stomatology, Prishtina, Kosovo \\ ${ }^{2}$ Department of History \& Archeology, University of Prishtina, Faculty of History, Prishtina, Kosovo \\ ${ }^{3}$ Museum of Kosova, Institute of Archeology, Prishtina, Kosovo \\ ${ }^{4}$ Oral Medicine \& Periodontology, University of Prishtina, Faculty of Medicine/Stomatology, Prishtina, Kosovo \\ Email: ferit.kocani@uni-pr.edu
}

Received 28 September 2011; revised 5 November 2011; accepted 2 December 2011

\begin{abstract}
Aim: To describe the presence, frequency of attrition in permanent dentition of human skulls from two ancient archeological locations. Aims: To determine the rate of attrition using a specific quantitative and qualitative method. Methods: Twenty one human skulls from two ancient archeological necropolises (Vendenis and Municipium Dardanorum DD) were included in the analysis of samples for this study. A total of 498 teeth were present in all human skulls. The skulls (with their accompanying teeth) were then divided into groups according to locality of origin, age and sex. Macroscopic (observational) analysis of the teeth relied on inspection and exploration of the teeth in their totality. The classification system that was used to rate tooth wear was Tooth Wear Index (TWI). Statistical analysis used: Chi-test for small samples was used to evaluate the observations obtained from the study. Multiple Logistic Regression Analysis was not performed due to the small number of teeth and the content of zero values in respective age groups. Results: The results show that out of total 498 teeth, $89.35 \%$ had attrition and $10.65 \%$ had no attrition or Grade 0 TWI. 21.48\% were Grade 1, 28.71\% Grade 2, $26.90 \%$ Grade 3, 7.42\% Grade 4 and $4.81 \%$ Grade 5. Conclusions: Grade 2 and higher rate of attrition, was predominantly present in first permanent molars.
\end{abstract}

Keywords: Abrasion; Attrition; Tooth Wear; Ancient Human

\section{INTRODUCTION}

Due to historical developments in Kosovo region, the amount of archaeological data available was both scarce and fragmental. Since the opportunity to provide bio archaeological data related to this region is relatively rare the aim of this study was to present our observations of archaeological data originating from a site rich in its history and heritage.

Tooth attrition is a domain of dental anthropology research that interprets pathological conditions and their influence on social processes. Identification of pathological conditions indicates processes in health and disease of a population and provides understanding of the process of adaptation, as well as partial recreation of history of the population in time and space [1-3].

Based on the bio archaeological research of the antiquity, Vendenis, Glamnik, near Podujeva and Municipium Dardanorum DD, Soçanica [4] near Mitrovica in Antique Dardania, today's Kosovo, in two necropolises were investigated.

Municipium Dardanorum DD is a habitat of the antiquity period in the antique Dardania. It was an important economy city and a centre of mining exploitation. It is situated near Soçanica village north of Mitrovica. This habitat was built in the third century A.D. when it gained its status of Municipium (Ptolomeo, II century A.D., "Geographia" Anonim from Ravena "Cosmographia" (IV, 15) \& Late Roman Settlement, Tabula Peutingeriana, Itineraria Romana, Segmentum VII \& VIII).

In this study, skeletal remnants and teeth in particular were analyzed to determine the grade of occlusal attrition.

Tooth analysis in general was performed by standardizing the characteristics and variables for their identification [5]. In skeletal remains, teeth are valuable sources of information regarding age, diet, and health. Tooth wear is especially helpful in reconstruction of dietary patterns in populations of varying subsistence. To illustrate variations of human tooth remains, anthropologists and bioarchaeologists contribute with interpretation of past health patterns, life styles, nutrition, behavior, nutritional stresses and biological interaction in ancient and recent popula- 
tions [6-12]. Different dental features offer detailed information on health status of past population, such as linear enamel hypoplasias, calculus formation, periodontal disease, caries, and periapical lesions [13].

Oral health and tooth wear have been studied in relation to diet and dietary trends, relationship between tooth wear and subsistence, food preparation, and the habitual use of teeth. The process of tooth wear begins with enamel loss and is followed by secondary dentin deposition. Tooth wear may have resulted from a variety of processes, including attrition, abrasion, and erosion. These different types of tooth wear may individual and/or groups of teeth, but all result in loss of tooth substance [14-17]. The main cause of tooth wear in prehistoric populations appears to have been due to some combination of friction of exogenous material forced over tooth surfaces and an increase in the number of power strokes during mastication when less refined, tougher foods are consumed $[18,19]$.

Attrition is a type of tooth wear produced by the contact between adjacent and opposing teeth. This induced wear is in a shape of facets on the occlusal or proximal surfaces at the level of contact points of the teeth [20].

Abrasion is a type of tooth wear induced not by the contact between the teeth and does not produce clear facets, but it is observed as wear of tooth detail $[21,22]$. Details on tooth surface are lost in contact with abrasive food particles and cheek-tongue type of biting [23-27].

Many authors have described occlusal attritional rate. A series of modal forms graded from A through $\mathrm{H}$ illustrating the standard diagram that reflects dentinal exposure was developed [28]. A summary of Murphy's diagram system that is now widely used in age determination was also created. The system is based on a similarity with Murphy's by adding the exposure of secondary dentin and by dividing the facets into grades of attrition as well as direction and shape of the wear [29]. A more complex system has been developed [30] for molar teeth attempting to avoid secondary dentin since the size of pulp chamber is variable in individuals.

A different method of scoring occlusal wear of molar teeth by describing in detail variations derived from an experiment, was also developed [31]. Systems for calculating the direction of the facet are developed $[32,33]$. The facets itself may be measured by taking pictures of the occlusal surfaces with a planimeter with a digital plate of a computerized system [34,35]. Occlusal attrition model and gradient usually are a small difference in tooth wear between left and right sides of the dentition. Many researchers measure the rate of attrition of the left side separate from the right side of the dentition when the missing teeth are on the opposite sides [36].

Lower molars have a slight advantage over maxillary molars and progressively as they emerge the wear pattern appear first in the first molar, then the second and so forth.

A small difference of attritional rate in different populations was found; while no significant difference between males and females in an absolute rate of attrition of teeth was observed [37]. There was however a highly significant difference in females [38]. Attrition rate is variable between populations. In hunters, e.g. rapid wear with high attritional rate occurs in frontal teeth as compared to farmers [39].

Wear rate has also been studied with the principles of axis method that presents the relation between the wear rate in two parameters, obliqueness and interruption [40, 41]. The steepness represents the difference in the average wear rate therefore high steepness observed suggests that the first molar has rapidly worn and relative to the second molar.

\section{MATERIAL AND METHODS}

Twenty one human skulls from the archeological necropolis of the antiquity period located in Vendenis, and Municipium Dardanorum DD, were used in the study. There were 13 male and 8 female skeletons with total of 498 teeth (See Table 1).

During excavation in these necropolises there were two methods of burial found. Historical data reveal that the people escorted their dead by either burial, incineration or in sarcophaguses (Inhumation, incineration and sarcophagus) (Figure 1).

Scientific methods for recording were developed with special emphasis on assessing teeth. The concept of recording methodology was based on the research experience of many authors. The records included the status of the present teeth, of each individual and groups of teeth (presence and rate of occlusal attrition, radiology evaluation of anomalies of teeth emergence and replacement as well as orthodontic relationships (in cases where both jaws were present). Information on sex, age, and the time period from which the specimens originated was obtained from documents (Museum of Kosovo, Department of Archaeology).

In this study we presented the analysis of the status of the teeth and the occlusal attrition attempting to provide some proof on the method of food processing, type,

Table 1. Distribution of skulls by location, sex and number of teeth.

\begin{tabular}{ccccc}
\hline Location/Necropolis & Skulls & Male & Female & Teeth \\
\hline Vendenis & 13 & 8 & 5 & 312 \\
Municipium Dardanorum DD & 8 & 5 & 3 & 186 \\
Total & 21 & 13 & 8 & 498 \\
\hline
\end{tabular}




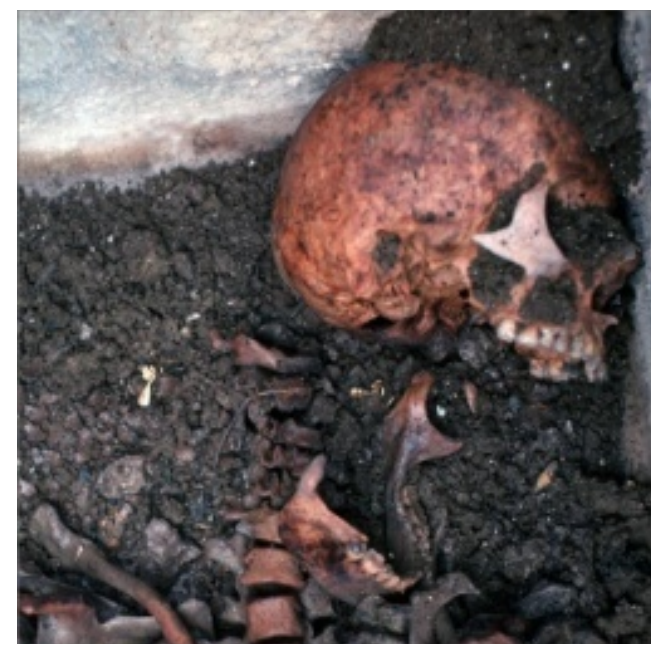

Figure 1. Sarcophagus inside.

consumption and behavior, since vast defects and macroscopic analyses of the teeth may reflect health and nutritional stress.

Macroscopic (observational) analysis of the teeth relied on inspection and exploration of the teeth in their totality. The classification system that was used to rate tooth wear was Tooth Wear Index (TWI) as follows:

Grade $0-$ no apparent wear, Grade $1-$ tooth wear is only apparent in enamel, Grade 2-partial exposure of the dentin, including almost half of the occlusal surface, Grade 3-the dentin is exposed in more than half of the occlusal surface, while there is still presence of enamel in some places, Grade 4-total exposure of the dentin, without opening of the pulp cavity, and Grade 5-high tooth wear leading to pulp cavity opening.

In absence of certain parameters to differentiate and impossibility for clear verification between these two processes, the terms attrition and abrasion were used and analyzed interchangeably. The results obtained derive from the actual status that was found regardless if the tooth substance loss might have occurred due to physiological or pathological processes considering that abrasion is a complex process that in itself contains the process of attrition.

For the comparison of the samples Chis-quare statistical method was used. Multiple Logistic Regression Analysis was not performed due to the small number of teeth and the content of zero values in respective age groups.

\section{RESULTS}

Results of the study are presented in table format for each necropolis and individual jaw.

Grade zero, no abrasion, in both necropolises, for both jaws there are a total of 53 teeth (10.64\%). Table 2 present the rate of abrasion graded 0 to 5 according to TWI classification in a cumulative form for all the skulls.
Graph 1 presents the average wear scores based on five-grade system reflecting the data derived in Table 2. The line inclines steeply at Grade 1 at 107 teeth (21.48\%), continues with a higher number of worn teeth Grade 2 reaching the plateau at 143 teeth $(28.71 \%)$. Grade 3 the line declines at 134 teeth (26.90\%). The line rapidly declines at Grade 4 with 37 teeth (7.42\%) and Grade 5 at 24 teeth $(4.81 \%)$.

Comprehensive analysis reveals that the teeth with no abrasion have been in function for a very short time following their eruption; in fact, they have suffered tooth wear immediately after eruption. Over the third of the teeth fit into Grade 2 and 3 of attrition and with such high grade of abrasion they have retained their qualitative function and powerful mastication. Based on the studies of other authors, it may be concluded that at Grade three of abrasion the pulp was not seriously attacked yet since defensive forces are good with compensation and apposition of irregular dentin hence enabling protection from ingress of pathogens into the pulp tissue. Apositioned dentin as a protective barrier has brought to pulp retraction hence reducing the pulp cavity. These way teeth remained vital even after considerable loss of tooth structure. In Grade 4 and 5, the involvement of pulpal chamber is evident with perforation of pulpal roof,

Table 2. Cumulative tooth wear rate of the teeth for all human skulls in the study.

\begin{tabular}{ccc}
\hline TWS & $\mathrm{N}$ & $\%$ \\
\hline 0 & 53 & 10.64 \\
1 & 107 & 21.48 \\
2 & 143 & 28.72 \\
3 & 134 & 26.90 \\
4 & 37 & 7.42 \\
5 & 24 & 4.81 \\
Total & 498 & 100.0 \\
\hline
\end{tabular}

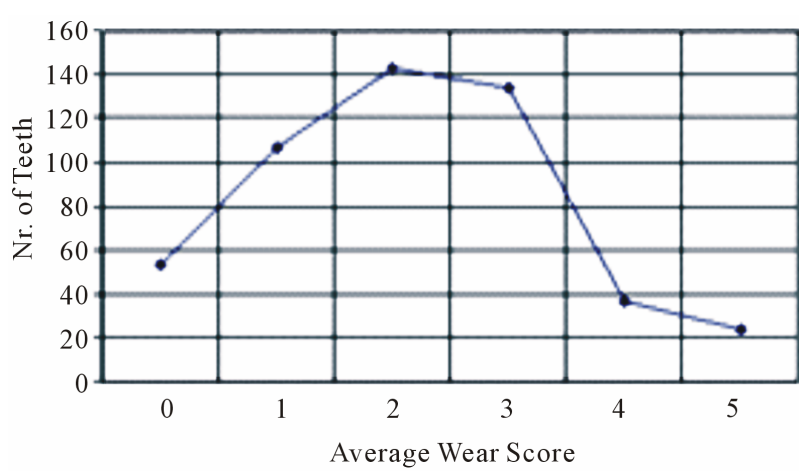

Graph 1. Average wear scores based on five-grade. 
which is an irreversible process with further conesquences to the periodontium and periapical region of the teeth.

\subsection{Vendenis}

The analysis of the teeth with Grade 2 or higher attrition rate was most evident in first molar (M1). Grade 2 and 3 was recorded in 21 out of 33 first molars of the maxilla (63.63\%) (Table 3), and in 43 out of 61 the first molars in the mandible (70.49\%) (Table 4).

Cumulative analysis reveals that out of 94 first molar teeth in both jaws, 64 were Grade 2 and 3 (68.08\%). Such high grade of wear in this tooth may be argued with the time of its emergence, in fact this is the first permanent tooth erupting at age six/seven and it enters masticator function very early (Figure 2).

Second most affected group of teeth at Grade 2 and 3 are second molars (M2) (68.75\%). Out of 64 teeth 44 are at Grade 2 and 3. Third most affected teeth with Grade 2 and 3 are second bicuspids (P2). Out of 46 teeth 23 were Grade 2 and 3 (50.00\%). Later on are first bicuspids (P1) where out of 42 teeth, 22 are involved (52, 38\%). Canines (C), out of 30 teeth 15 are Grade two and three (42.5\%). Central incisors (I1), 7 (46.66\%) out of 15 teeth, lateral incisors 5 (I2) (33.33\%) out of 15 teeth.

Grade 4 of occlusal attrition in all teeth from Vendenis necropolis is present at $6.73 \%$. Twenty one out of 312 teeth analyzed had Grade 4 attrition wear. Grade 5 occlusal attrition in Vendenis necropolis is present at 3.84\%. Twelve out of 312 analyzed teeth had Grade 5 occlusal attrition.

\subsection{Municipium Dardanorum DD}

In location of Municipium Dardanorum DD, (Tables 5 and 6) out of total 49 first molars (M1), 32 (81.1\%) of the teeth were Grade 2 and 3 . The second molar (M2) (48.9\%), out of 47 teeth 23 were Grade 2 and 3. In this

Table 3. Occlusal attrition of maxillary teeth in skulls from Vendenis necropolis.

\begin{tabular}{cccccccccc}
\hline \multicolumn{7}{c}{ Tooth } \\
\hline TWS & I1 & I2 & C & P1 & P2 & M1 & M2 & M3 & Total \\
\hline 0 & 2 & 3 & 3 & 1 & 2 & 3 & 1 & 0 & 15 \\
1 & 1 & 3 & 2 & 5 & 7 & 6 & 5 & 2 & 31 \\
2 & 2 & 2 & 4 & 7 & 9 & 12 & 7 & 0 & 43 \\
3 & 1 & 2 & 5 & 6 & 7 & 9 & 8 & 0 & 38 \\
4 & 2 & 1 & 4 & 3 & 1 & 1 & 2 & 0 & 14 \\
5 & 0 & 0 & 0 & 1 & 1 & 2 & 1 & 0 & 5 \\
Total & 8 & 11 & 18 & 23 & 27 & 33 & 24 & 2 & 146 \\
\hline
\end{tabular}

Table 4. Occlusal attrition of mandibular teeth in skulls from Vendenis necropolis.

\begin{tabular}{cccccccccc}
\hline \multicolumn{7}{c}{ Tooth } \\
\hline TWS & I1 & I2 & C & P1 & P2 & M1 & M2 & M3 & Total \\
\hline 0 & 0 & 0 & 1 & 2 & 3 & 2 & 1 & 2 & 11 \\
1 & 3 & 3 & 5 & 7 & 6 & 9 & 7 & 2 & 42 \\
2 & 3 & 1 & 4 & 7 & 5 & 17 & 11 & 0 & 48 \\
3 & 1 & 0 & 2 & 2 & 2 & 26 & 18 & 0 & 51 \\
4 & 0 & 0 & 0 & 1 & 2 & 3 & 1 & 0 & 7 \\
5 & 0 & 0 & 0 & 0 & 1 & 4 & 2 & 0 & 7 \\
Total & 7 & 4 & 12 & 19 & 19 & 161 & 40 & 4 & 4 \\
\hline
\end{tabular}

Table 5. Occlusal attrition of maxillary teeth in Municipium Dardanorum DD necropolis.

\begin{tabular}{cccccccccc}
\hline \multicolumn{7}{c}{ Tooth } \\
\hline TWS & I1 & I2 & C & P1 & P2 & M1 & M2 & M3 & Total \\
\hline 0 & 2 & 2 & 2 & 1 & 1 & 0 & 1 & 4 & 13 \\
1 & 1 & 0 & 1 & 2 & 2 & 3 & 4 & 1 & 14 \\
2 & 2 & 1 & 3 & 4 & 4 & 7 & 5 & 0 & 26 \\
3 & 0 & 1 & 1 & 2 & 1 & 9 & 7 & 0 & 21 \\
4 & 0 & 0 & 0 & 1 & 1 & 2 & 3 & 0 & 7 \\
5 & 0 & 0 & 0 & 0 & 0 & 3 & 2 & 0 & 5 \\
Total & 5 & 4 & 7 & 10 & 9 & 24 & 22 & 5 & 87 \\
\hline
\end{tabular}

Table 6. Occlusal attrition of mandibular teeth in Municipium Dardanorum DD necropolis.

\begin{tabular}{cccccccccc}
\hline \multicolumn{1}{c}{ Tooth } \\
\hline TWS & I1 & I2 & C & P1 & P2 & M1 & M2 & M3 & Total \\
\hline 0 & 1 & 2 & 1 & 2 & 1 & 2 & 2 & 2 & 13 \\
1 & 3 & 1 & 0 & 3 & 2 & 3 & 7 & 1 & 20 \\
2 & 3 & 1 & 2 & 4 & 6 & 7 & 3 & 0 & 26 \\
3 & 0 & 0 & 0 & 2 & 5 & 9 & 8 & 0 & 24 \\
4 & 0 & 0 & 0 & 1 & 3 & 2 & 3 & 0 & 9 \\
5 & 0 & 0 & 0 & 1 & 2 & 2 & 2 & 0 & 7 \\
Total & 7 & 4 & 3 & 13 & 19 & 25 & 25 & 3 & 99 \\
\hline
\end{tabular}

necropolis it is interesting the level of Grade 2 and 3 involvements of the canine teeth (C). Out of 10 canine teeth 6 had Grade 2 and 3 involvements. Then in the sequence follow central incisors (C1) 50\%, first bicuspids (P1) 46.8\%, and second bicuspids (P2) 42.8\% and lateral incisors (I1) $37.5 \%$. 
Grade 4 of occlusal attrition in teeth from Municipium Dardanorum DD is present at $8.60 \%$. Sixteen out of 186 teeth had Grade 4 attrition. Grade 5 occlusal attrition in teeth from Municipium Dardanorum is present at $6.45 \%$. Twelve out of 186 teeth had Grade 5 attrition. There are 14 third molars (M3) in total in both necropolises and both jaws and six of the teeth had Grade one attrition 42.85\%, and 47.15\% had Grade zero. Attrition rate in these teeth does not exceed Grade one attrition most probably related to the time of eruption (17 - 27 years) and its position in the dental arch and the jaws (Figure 3).

In Vendenis necropolis out of total 13 skeletons, 8 (61.54\%) were male and 5 (38.46\%) female skeletons. In Municipium Dardanorum (DD) out of 8 skeletons that were analyzed, 5 (62.5\%) were male and 3 (37.5\%) female skeletons. Cumulative total in both necropolis were 13 (61.90\%) male and 8 (38.10\%) female skeletons (See Table 1).

Statistical analysis on the prevalence of attritional wear by sex showed a difference with no considerable statistical significance between males and females. Chi-test (Male vs. Female) $=2.5, \mathrm{df}=5, \mathrm{p}=0.78$ (Table 7).

The anthropology data on the age of skeletons related to the TWS, case distribution according to the wear rate and age groups showed a significant statistical difference, Chi-test $=197.8, \mathrm{df}=20, \mathrm{p}<0.001$ (Tables 8, 9 and Graph 2).

Multiple Logistic Regression Analysis (Table 10) for TWS $=0$, TWS $=4$ and TWS $=5$ was not performed due to the small number of teeth and the content of zero values in respective age groups.

According to the multiple logistic regression analysis a risk rate for the occurrence of TWS $=1$ increases with age groups $25-35,35$ - 45 and about 40 , at 1.7 times, 1.2 times and 1.1 respectively compared to 17 - 25 age group.

The risk rate for the occurrence of TWS $=2$ increases in age groups $25-35,35-45$, and about 45 , for 3.8 times, 3.1 times, 4.5 times and 1.7 times, respectively as compared to 17 - 25 age group.

The risk rate for the occurrence of TWS $=3$ increases over time, hence in the age groups 25 - 35, 35 - 45, and about 40 , this risk increases for 6.8 times, 19.8 times, 18 times, respectively as compared to 17 - 25 age groups.

According to this analysis we concluded that the risk of occurrence of higher wear grade (TWS) increases over time.

\section{DISCUSSION}

Human dentition in the past differs strictly from those of contemporary people on the degree of tooth wear. In past populations wear was ubiquitous, intense, abrasive and

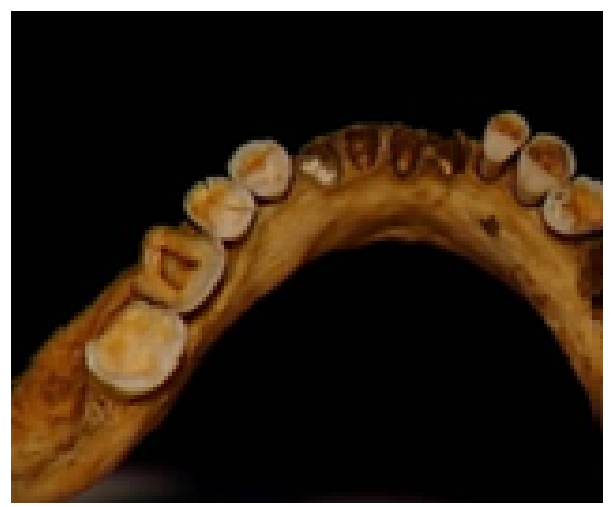

Figure 2. Higher rate of attrition predominantly present in first permanent molar.

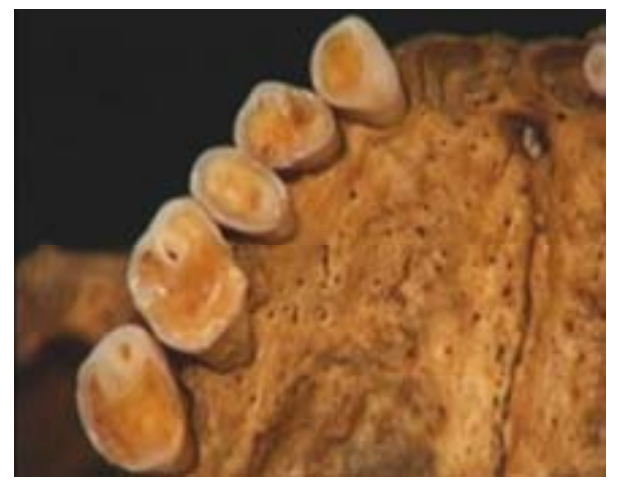

Figure 3. Loss of tooth substance as well as attrition direction.

Table 7. Prevalence of tooth wear by sex.

\begin{tabular}{ccccc}
\hline \multicolumn{5}{c}{ Prevalence of tooth wear } \\
\hline TWS & Male & Female & $\mathrm{N}$ & $\%$ \\
\hline 0 & 31 & 22 & 53 & 10.64 \\
1 & 67 & 40 & 107 & 21.48 \\
2 & 91 & 52 & 143 & 28.72 \\
3 & 86 & 48 & 134 & 26.90 \\
4 & 19 & 18 & 37 & 7.42 \\
5 & 15 & 9 & 24 & 4.81 \\
Total & 309 & 189 & 498 & 100.0 \\
\hline
\end{tabular}

physiological as it was related to their food and their technologies. In these populations, it affected the proximal and occlusal surfaces which modified the occlusal plane profoundly [6-10]. To categorize the amount of wear, many different classification systems are used, from which we can determine diet, cultural changes and the age at death of individuals $[21,29]$. They also illustrate the evolution of certain functional dental and skeletal compensations in the masticatory apparatus such as continuous dental eruption, mesial drift of the arches and 
Table 8. Distribution TWS by age.

\begin{tabular}{cccccc}
\hline \multicolumn{7}{c}{ Age } & & \\
\hline TWS & $17-25$ & $25-35$ & $35-45$ & About 45 & Total \\
\hline 0 & 29 & 12 & 7 & 5 & 53 \\
1 & 14 & 20 & 28 & 45 & 107 \\
2 & 8 & 22 & 36 & 77 & 143 \\
3 & 2 & 11 & 47 & 74 & 134 \\
4 & 0 & 5 & 11 & 21 & 37 \\
5 & 0 & 2 & 7 & 15 & 24 \\
Total & 53 & 72 & 136 & 213 & 498 \\
\hline
\end{tabular}

Table 9. Brothwell system age estimation from attrition.

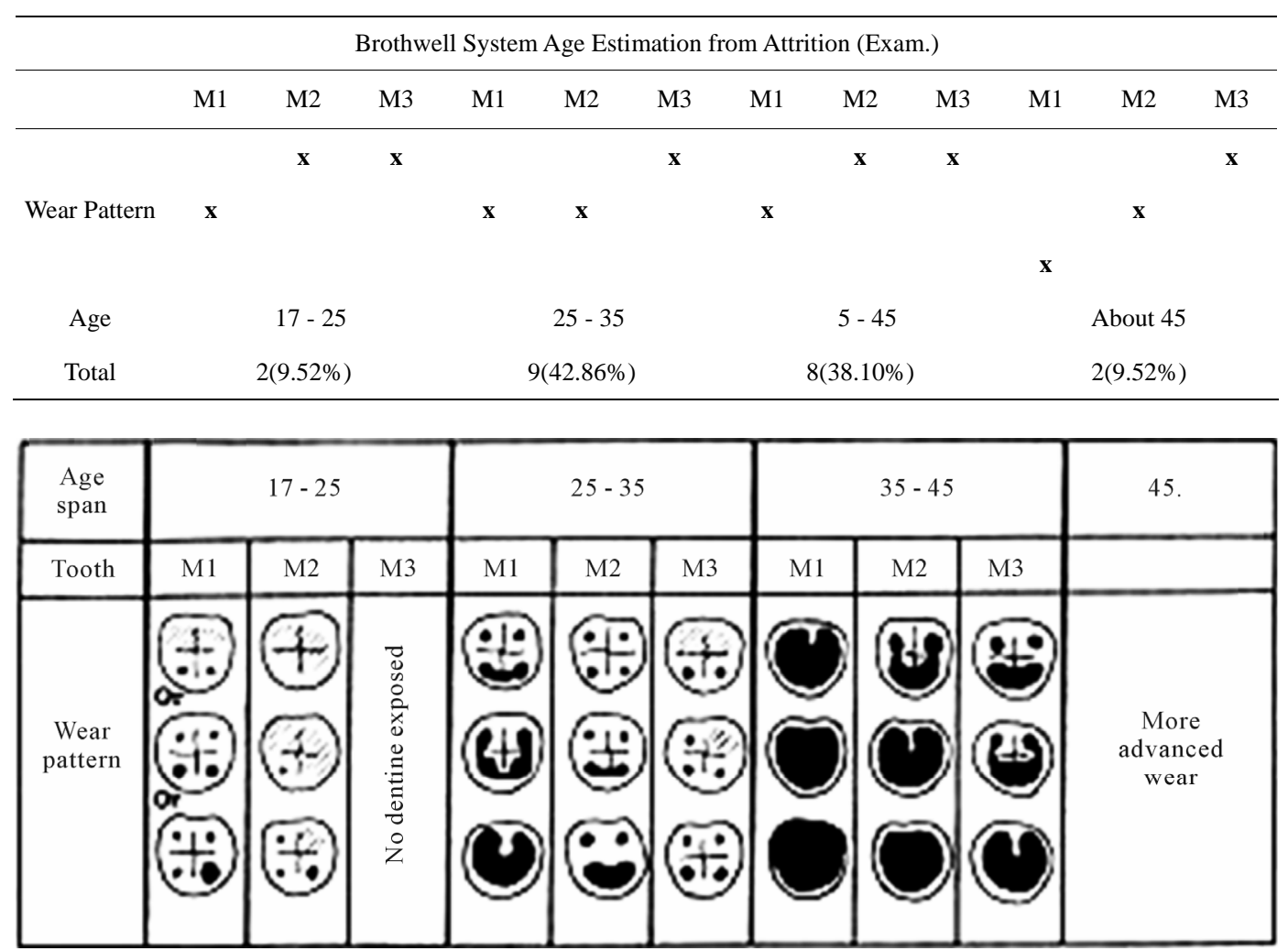

Graph 2. Brothwell's system age estimation from attrition. Reprinted from Dental Anthropology, Simon Hillson 1996, Cambridge University Press.

lingual tipping of incisors which can then be monitored [14]. These physiological adaptations related mainly to function and ontogenesis can also be found in presentday populations where wear is moderate, although they are much less obtrusive [19]. Wear is strictly speaking intentional or unintentional attrition or abrasion and is caused by human activity. Distinctions are made between unintentional (passive) and intentional (active) habitual tooth wear. Unintentional modifications include dietary, parafunctional, occupational, traumatic, and habitual dental marks, as well as erosion. Intentional modifications include deliberate extractions, fillings, decorations and early dentistry [42]. Extramasticatory (habitual) dental wear, such as, notching and grooving $[43,44]$ are described as “an indentation involving the tooth's incisal/ occlusal edges, sometimes extending across all the surface" depicted from epipalaeolithic necropolis of Taforalt (Morocco), skeletal remains from the Neolithic to Medieval times in England [45] and the United States $[46,47]$. Similar changes have been recorded in recent 
Table 10. Multiple logistic regression analysis, dependent variable-TWS vs. independent variables (age group).

\begin{tabular}{ccccccc}
\hline Dependent Variable & Ind. Variable & Coefficient & Std. Error & Odds Ratio & Conf. Lower 5\% & Conf. Upper 95\% \\
\hline \multirow{2}{*}{ TWS1 } & (17 - 25) & -1.5 & 0.3 & $\mathbf{0 . 2}$ & 0.1 & 0.4 \\
& RC-25-35 & 0.5 & 0.4 & $\mathbf{1 . 7}$ & 0.8 & 3.8 \\
& RC-35-45 & 0.2 & 0.4 & $\mathbf{1 . 2}$ & 0.6 & 2.4 \\
& About-45 & 0.1 & 0.3 & $\mathbf{1 . 1}$ & 0.6 & 2.2 \\
\multirow{7}{*}{ T } & (17 - 25) & -2.2 & 0.4 & $\mathbf{0 . 1}$ & 0.1 & 0.2 \\
& RC-25-35 & 1.3 & 0.5 & $\mathbf{3 . 8}$ & 1.6 & 9.2 \\
& RC-35-45 & 1.1 & 0.4 & $\mathbf{3 . 1}$ & 1.4 & 7.1 \\
& About-45 & 1.5 & 0.4 & $\mathbf{4 . 5}$ & 2.1 & 9.9 \\
& (17-25) & -3.6 & 0.7 & $\mathbf{0 . 0}$ & 0.0 & 0.1 \\
& RC-25-35 & 1.9 & 0.8 & $\mathbf{6 . 8}$ & 1.4 & 31.7 \\
& RC-35-45 & 3.0 & 0.7 & $\mathbf{1 9 . 8}$ & 4.7 & 84.3 \\
& About-45 & 2.9 & 0.7 & $\mathbf{1 8 . 0}$ & 4.3 & 75.3 \\
\hline
\end{tabular}

human cases of carpenters, tailors, and shoemakers [48], as well as modern examples of "pen-biting" [49]. Occlusal grooving appears as single or multiple, well-defined, grooves on anterior teeth [50]. The grooves have been observed in dentitions from different time periods and geographical areas and have been attributed to the working of willow strands, fibres, and sinews. Interproximal grooves are generally located at or near the cementoenamel junction on the approximal surfaces the teeth. They have been reported to occur most frequently in premolar and molar teeth [51]. Molnar et al. [42], in the Swedish Middle Neolithic sample Ajvide, and Schulz et al. [52] among prehistoric populations from the Stone Lake site in California, recorded interproximal grooves in all tooth types except the molars. They interpret interproximal grooving as result of stripping animal sinews between clenched posterior teeth in an aboriginal sample, or caused by a more solid, nonflexible object with a defined shape [53], Wallace et al. [54] consider the changes as remnants of dietary grit in food and drinks during swallowing. Extramasticatory use of teeth also had effects on people's health in the past. Pathological changes include periapical lesions, lingual tilting, chipping, antemortem tooth loss, and temporomanibular change (Figure 4).

Several studies have shown a correlation between tooth wear and periapical lesions [55,56]. The bacteria spread through the root canal or through fine cracks in the occlusal surface and into the periapical region through the apical foramen or alongside the root. Because of the severe attrition, the pulp is exposed, thus giving access to bacteria to enter. On the other hand, when sever attrition is placed on a tooth; the force will

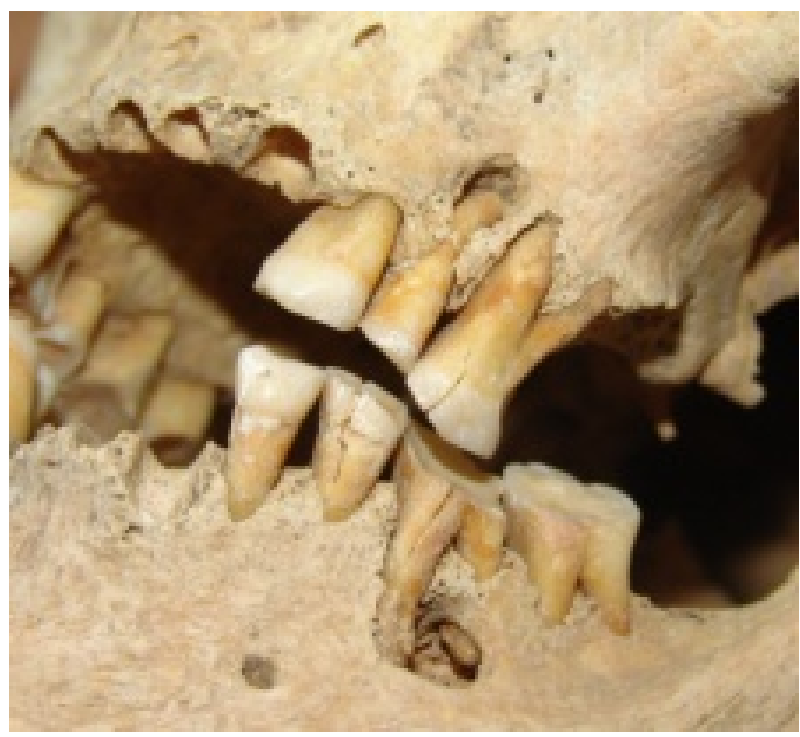

Figure 4. Lower and upper jaw, more advanced wear on tooth 36 (more of 45 old male from Vendenis), showing a periapical lesions at second upper second premolar and first mandibular molar, buccal tilting of the first and second molar, an chipping of molars. Note also the big aperture of the pulp chamber on the first molar.

bring the tooth to dislocate itself from its original position in the jaw. The emergence of periapical lesions in areas of affected teeth is most likely a contribution factor in this process [57]. Severe crushing of hard materials and/or the presence of seeds and gravel in the food is believed to the cause of microfractures in the enamel and dentine [58]. Small lesions often occur in prehistoric context and are generally found in all regions of the dental arch. One of the primary causes of the antemortem 
tooth loss is wear in correlation with dietary, nutritional and traumatic factors [59]. In general, frequencies of antemortem tooth loss due to heavy wear and caries affect the posterior teeth, while loss of teeth in the anterior arch is caused by extramasticatory behavior. Anterior teeth are lost as they are not as well attached in the jaw as teeth with multiple roots [60]. Finally, there are of positive correlation between heavy tooth wear and changes in the temporo-mandibular joint, emphasize the use of joint change in the TMJ for determining bilateral asymmetry in tooth wear [61].

Apart from certain pathological cases associated with a specific parafunction, iatrogenic tooth brushing or an eating disorder and encouraged by an acid environment, they are the result of a physiological process that should not be halted [17].

Abrasion is the predominant wear mechanism caused by the mastication of hard fibrous material, typical of hunter-gatherer populations, especially those living in desert environments. In such populations, individuals of all ages show evidence of abrasion on both enamel and in dentine when exposed. It is also well established that abrasion has a direct linear association with age [31]. Although this relationship tends to become exponential with molar wear during old age, it nevertheless highlights that the general diet and hence its abrasive potential remains relatively constant within a set environment. Attrition occurs from tooth-to-tooth contact without the presence of food and typically is characterized by the facet that is matched by a corresponding facet on a tooth in the opposing arch. Erosion can be defined as the chemical dissolution of tooth substance without the presence of plaque. The clinical appearance has been well documented [17], The mechanisms of attrition, abrasion and erosion act together, each with different intensity and duration to produce a multitude of different wear patterns. The interplay between attrition and abrasion has been demonstrated with casts from longitudinal growth studies of the same individuals of pre-contemporary aboriginal populations [20]. Wear is strictly speaking intentional (active) or unintentional attrition or abrasion and caused by human activity. Distinctions are made between unintentional (passive) and intentional (active) habitual teeth wear.

Variations to the degree and pattern of tooth wear between populations are attributed to the abrasiveness of the diet and the use of teeth as tools [1].

Analysis of high Grade of attrition in necropolis Vendenis and Municipium Dardanorum DD of the period of antiquity second and fourth century A.D. of Dardania culture can be justified with the technology of processing and the cultivated agriculture [39].

Abrasive effects of the food consumed surely have contributed in tooth wear, however not at a rate of pre- sent attrition rate. These factors have an input in the found pathology, however for such a high grade of tooth wear most necessarily other factors should be present.

Agriculture in antique Dardania was one of the important enterprises. They grew wheat, barley, millet, beans and lentils. For baking bread, they used furnaces. These furnaces were made of clay and served for boiling and baking of various foods. They also grew animals such as pigs, sheep, goats and less frequently cows.

They manufactured copper, gold, silver, and later on iron. Also had knowledge of glass manufacturing and out of these glass pastes they made glass marbles for decorations on their fibulae and for necklaces [62].

Grain products were milled by hand mills and later one by stone mills. Evidently, the wheels put in motion besides milling the grains in between, due to permanent friction necessarily they must have milled also the milling stones and the final product contained stone particles that have exerted unavoidable abrasive forces to the consumer [63].

Hard physical activity can accelerate tooth wear process, which increase higher masseteric activity and consequently induce tooth clenching and grinding [27]. Based on archeological and historical data Dardans in this $\mathrm{Mu}-$ nicipium (habitat) were mining workers close to their habitat. They also were involved in metal processing that means artisanship and mastery of metal manufacture for various purposes.

Regardless of the etiological factors causing high grade of occlusal attrition in teeth, it is a general conclusion from this study following the analysis of attrition rate in these two necropolis of antiquity period in the region of Dardania of Illyrian culture, this population had well developed jaws with a powerful mastication system. Explaining that the TWI Score 3 and high tooth wear of this stage were the consumption of natural, crude and abrasive foods [64] or the presence of abrasive substance in food accompanied by powerful mastication.

It is evident that out of the total number of analyzed skulls (21) and teeth (498) in both locations, no anomalies of the position of the teeth in dental arches were noted.

On the skull 13 (Figure 5) found in the stone made sarcophagus an anomaly of persistence (probable ankylosis) is noted of a deciduous left second molar tooth [65], also agenesis of the succeeding permanent second bicuspid and third permanent molars (partial anodontia) in both jaws and both sides are noted (third molars, never erupted, probable agenesis (Figure 6).

While in skull 12 (Figure 7) is noted a peg-shaped maxillary lateral incisor (22), or conical crown-size reduction [66].

It can be concluded that there is a high grade of tooth attrition in both necropolis in antique period, Vendenis and 


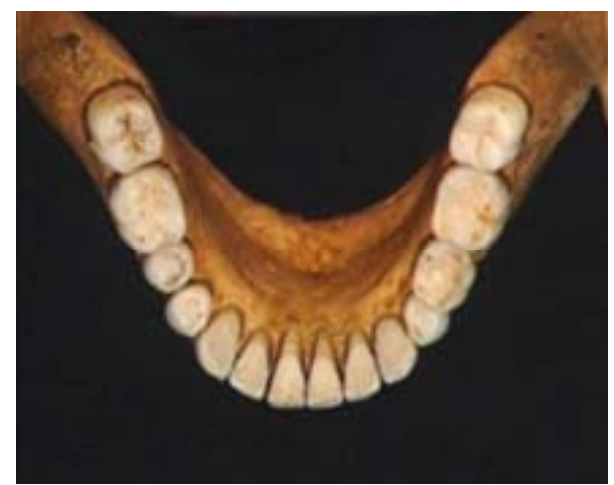

Figure 5. Anomaly of persistence of a deciduous left second molar tooth.

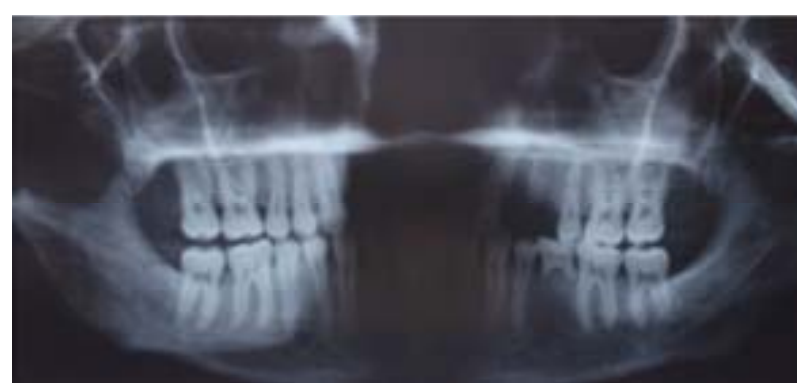

Figure 6. Orthopantomogram (OTP) third molars never erupted, probable agenesia.

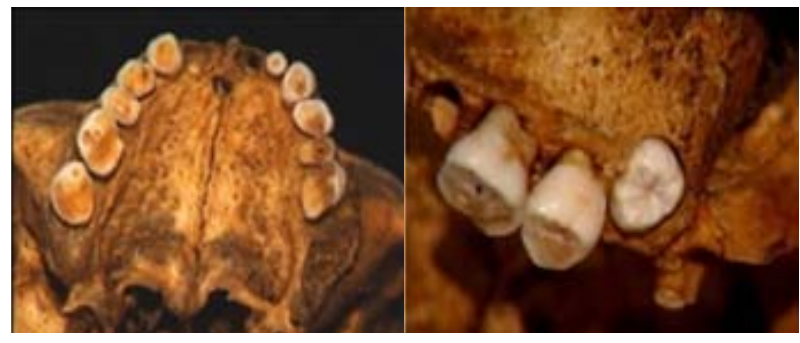

Figure 7. Peg-shaped lateral incisor (22). Figure 7 third molar not involved in occlusal wear processes.

Municipium Dardanorum, today's Kosovo. The causes of attrition should be sought in food quality and type and in the mode of processing.

\section{REFERENCES}

[1] Molnar, S. (1972) Tooth wear and culture: A survey of tooth functions among some prehistoric populations. Current Anthropology, 13, 511-526. doi:10.1086/201284

[2] Anderson, R. (1996) Science and Health. Harcourt Brace \& Company, New York.

[3] Baer Hans, A., Singer, M. and Susser, I. (1997) Medical Anthropology and the World System: A Critical Perspective. Bergin \& Garvey, Westport.

[4] Cerskov, E. (1970) Municipium DD at Soqanica. Museum of Kosovo, Archeological Society of Yugoslavia, Prishtina-Beograd, XIX/10-11, 60-61.
[5] Lundström, A. (1963) Tooth morphology as a basis for distinguishing monozygotic twins. American Journal of Human Genetics, 15, 34-43.

[6] Campbell, T.D. (1939) Food, food values and food habits of the Australian Aborigines in relation to their dental conditions. Australian Dental Journal, 43, 1-15.

[7] Smith, B.H. (1984) Patterns of molar wear in huntergathers and agriculturalists. American Journal of Physical Anthropology, 63, 39-56. doi:10.1002/ajpa.1330630107

[8] Dean, M.C., Jones, M.E. and Pilley, J.R. (1992) The natural history of tooth wear, continuous eruption and peri- odontal disease in wild shot great apes. Journal of Human Evolution, 22, 23-39. doi:10.1016/0047-2484(92)90027-7

[9] Lalueza Fox, C. and Frayer, D.W. (1997) Non-dietary marks in the anterior dentition of the Krapina Neanderthals. International Journal of Osteoarchaeology, 7, 133-149. doi:10.1002/(SICI)1099-1212(199703)7:2<133::AID-OA 326>3.0.CO;2-4

[10] Kaifu, Y. (1999) Changes in the pattern of tooth wear from prehistoric to recent periods in Japan. American Journal of Physical Anthropology, 109, 485-499. doi:10.1002/(SICI)1096-8644(199908)109:4<485::AIDAJPA5>3.0.CO;2-K

[11] Turner, C.G. and Cheuiche Machado, L.M. (1983) A new dental wear pattern and evidence for high carbohydrate consumption in a Brazilian archaic skeletal population. American Journal of Physical Anthropology, 61, 125-130. doi:10.1002/ajpa.1330610113

[12] Frederic, P, Pacciani, E and Gori, S. (2006) Age-at-death diagnosis by tooth wear: Reliability evaluation. A Bayesian model. In: Di Bacco, M., Frederic, P. and Scalfari, F., Eds., Bayesian Inference for Diagnosing Sex and Age at Death in Skeletal Remains. Diffusione Immagine Editore, Asti, 19-29.

[13] Eshed, V., Gopher, A. and Hershkovitz, I. (2006) Tooth wear and dental pathology at the advent of agriculture: New evidence from the Levant. American Journal of Physical Anthropology, 130, 145-159. doi:10.1002/ajpa.20362

[14] Belcastro, G., Rastelli, E., Mariotti, V., Consiglio, C., Facchini, F. and Bonfiglioli, B. (2007) Continuity or discontinuity of the life-style in central Italy during the Roman imperial age-early middle ages transition: Diet, health, and behavior. American Journal of Physical Anthropology, 132, 381-394. doi:10.1002/ajpa.20530 PMid:17154361

[15] Klatskey, M. (1939) Dental attrition. Journal of the American Dental Association, 26, 73-84.

[16] Davies, T.G.H. and Pedersen, P.O. (1955) The degree of attrition of the deciduous teeth and first permanent molars of primitive and urbanized Greenland natives. British Dental Journal, 99, 35-43.

[17] Grippo, J. (2004) Attrition, abrasion, corrosion and abfraction revisited. Journal of the American Dental Association, 135, 1109-1118.

[18] Berry, D.C. and Poole, D.F.G. (1976) Attrition: Possible 
mechanisms of compensation. Journal of Oral Rehabilitation, 3, 201-206.

doi:10.1111/j.1365-2842.1976.tb00945.x

[19] Russell, M.D. (1987) The distinction between physiological and pathological attrition: A review. Journal of the American Dental Association, 33, 23-31.

[20] Kaidonis, J.A. (2008) Tooth wear: The view of the anthropologist. Clinical Oral Investigations, 12, 21-26. doi:10.1007/s00784-007-0183-3

[21] Molnar, S. (1971) Human tooth wear, tooth function and cultural variability. American Journal of Physical Anthropology, 34, 175-190. doi:10.1002/ajpa.1330340204

[22] Jokstad, A. (2005) Wear of teeth due to occupational exposure to airborne olivine dust. Acta Odontologica Scandinavica, 63, 294-299. doi:10.1080/00016350510020052

[23] Enbom, L. (1986) Occlusal wear in miners. Swedish Dental Journal, 10, 165-70.

[24] Ash, M. (1993) Dental anatomy, physiology and occlusion. 7th Edition, W.B. Saunders, Philadelphia.

[25] Ash, M. and Ramfjord, S. (1995) Occlusion. 4th Edition, W.B. Saunders, Philadelphia.

[26] Bachanek, T. (1999) Exposure to flour dust and the level of abrasion of hard tooth tissues among the workers of flourmills. Annals of Agricultural and Environmental Medicine, 6, 147-149.

[27] Lavigne, G. and Kato, T. (2003) Usual and unusual orofacial motor activities associated with tooth wear. International Journal of Prosthodontics, 16, 10-12.

[28] Murphy, T. (1959) Compensatory mechanism in facial height adjustment to functional tooth attrition. Australian Dental Journal, 4, 312-323. doi:10.1111/j.1834-7819.1959.tb03727.x

[29] Molnar, S. (1971) Human tooth wear, tooth function and cultural variability. American Journal of Physical Anthropology, 34, 175-190. doi:10.1002/ajpa.1330340204

[30] Scott, C. (1979) Principal axis analysis of dental attrition data. American Journal of Physical Anthropology, 51, 203-211. doi:10.1002/ajpa.1330510207

[31] Dreier, F.G. (1994) Age at death estimates of the protohistoric Arikara using molar attrition rates: A new quantification method. International Journal of Osteoarchaeology, 4, 137-148. doi:10.1002/oa.1390040206

[32] Smith, B.G. and Knight, J.K. (1984) An index for measuring the wear of teeth. British Dental Journal, 156, 435438. doi:10.1038/sj.bdj.4805394

[33] Walker, P.L., Dean, G. and Shapiro, P. (1991) Estimating age from tooth wear in archaeological populations. In: Kelley, M.A. and Larsen, C.S., Eds., Advances in Dental Anthropology, Wiley-Liss, Chichester, 13-31.

[34] Molnar, S., McKee, J.K. and Molnar, I. (1983) Measurements of tooth wear among Australian Aborigines: I. Serial loss of the enamel crown. American Journal of Physical Anthropology, 61, 51-65. doi:10.1002/ajpa.1330610106

[35] Richards, L.C. and Miller, S.L.J. (1991) Relationship between age and dental attrition in australian aboriginals. American Journal of Physical Anthropology, 84, 159-164.

\section{doi:10.1002/ajpa.1330840205}

[36] Lavelle, C.L.B. (1970) Analysis of attrition in adult human molars. Journal of Dental Research, 49, 822-828. doi:10.1177/00220345700490042001

[37] Pal, A. (1971) Gradients of dentine exposure in human molars. Journal of the Indian Anthropological Society, 6, 67-73.

[38] McKee, J.K. and Molnar, S. (1988) Measurements of tooth wear among Australian aborigines: II. Intrapopulational variation in patterns of dental attrition. American Journal of Physical Anthropology, 76, 125-136. doi:10.1002/ajpa.1330760111

[39] Hinton, R.J. (1981) Form and patterning of anterior tooth wear among aboriginal human groups. American Journal of Physical Anthropology, 54, 555-564. doi:10.1002/ajpa.1330540409

[40] Richards, L.C. (1984) Principal axis analysis of dental attrition data from two Australian Aboriginal populations. American Journal of Physical Anthropology, 65, 5-13. doi:10.1002/ajpa.1330650103

[41] Benfer, R.A. and Edwards, D.S. (1991) The principal axis method for measuring rate and amount of dental attrition: Estimating juvenile or adult tooth wear from unaged adult teeth. In: Kelley, M.A. and Larsen, C.S., Eds., Advances in Dental Anthropology, Willey-Liss, New York, 325-340.

[42] Molnar, P. (2011) Extramasticatory dental wear reflecting habitual behavior and health in past populations. Clinical Oral Investigations, 15, 681-689. doi:10.1007/s00784-010-0447-1

[43] Barrett, M.J. (1977) Masticatory and nonmasticatory uses of teeth. In: Wright, R.V.S., Ed., Stone Tools as Cultural Markers: Change, Evolution and Complexity. Australian Institute of Aboriginal Studies, Canberra, 17-23.

[44] Begg, P.R. (1954) Stone age man's dentition. American Journal of Orthodontics, 40, 298-312, 373-383, 462-475, 517-531. doi:10.1016/0002-9416(54)90092-5

[45] Cruwys, E., Robb, N.D. and Smith, B.G.N. (1992) Anterior tooth notches: An Anglo-Saxon case of study. Journal of Paleopathology, 4, 211-220.

[46] Larsen, C.S. and Thomas, D.H. (1982) The anthropology of St. Catherine's Island: 4. the St. Catherine period mortuary complex. Anthropological papers of the American Museum of Natural History, 57, 271-342.

[47] Blakely, R. and Beck, L.A. (1984) Tooth use versus dental mutilations: A case study from the prehistoric Southeast. Midcontinental Journal of Archaeology, 9, 269-277.

[48] Kaifu, Y., Kasai, K., Townsend, G.C. and Richards, L.C. (2003) Tooth wear and the "design" of the human dentition: A perspective from evolutionary medicine. American Journal of Physical Anthropology, 122, 47-61. doi:10.1002/ajpa.10329

[49] Kvaal, S.I. and Derry, T.K. (1996) Tell-tale teeth: Abrasion from the traditional clay pipe. Endeavour, 20, 28-30. doi:10.1016/0160-9327(96)10006-5

[50] Larsen, C.S. (1985) Dental modifications and tool use in the western Great Basin. American Journal of Physical Anthropology, 67, 393-402. doi:10.1002/ajpa.1330670411 
[51] Fortelius, M. and Solounias, N. (2000) Functional characterization of ungulate molars using the abrasion-attrition wear gradient: A new method for reconstructing paleodiets. American Museum Novitates, 1-36. doi:10.1206/0003-0082(2000)301<0001:FCOUMU>2.0. $\mathrm{CO} ; 2$

[52] Schulz, P.D. (1977) Task activity and anterior tooth grooving in prehistoric California Indians. American Journal of Physical Anthropology, 46, 87-92. doi:10.1002/ajpa.1330460112

[53] Brown, T. and Molnar, S. (1990) Interproximal grooving and task activity in Australia. American Journal of Physical Anthropology, 81, 545-553. doi:10.1002/ajpa.1330810410

[54] Wallace, J.A. (1974) Approximal grooving of teeth. American Journal of Physical Anthropology, 40, 285-290. doi:10.1002/ajpa.1330400310

[55] Dias, G., Prasad, K. and Santos, A.L. (2007) Pathogenesis of apical periodontal cysts: Guidelines for diagnosis in paleopathology. International Journal of Osteoarchaeology, 17, 619-626. doi:10.1002/oa.902

[56] Alt, K.W., Wächter, R. and Türp, J.C. (1992) Pulpoalveolar disease: Etiology, incidence, and differentiation of periapical lesions. Journal of Paleopathology, 4, 163-178.

[57] Clarke, N.G. and Hirsch, R.S. (1991b) Physiological, pulpal, and periodontal factors influencing alveolar bone. In: Kelley, M.A. and Larsen, C.S., Eds., Advances in Dental Anthropology, Wiley-Liss, New York, 241-266.

[58] Molleson, T. and Jones, K. (1991) Dental evidence for dietary change at Abu Hureyra. Journal of Archaeological Science, 18, 525-539.
[59] Lukacs, F.R. and Pal, J.N. (1993) Mesolithic subsistence in North India: Inferences from dental attributes. Current Anthropology, 34, 745-765. doi:10.1086/204220

[60] Lukacs, J.R. (2007) Dental trauma and antemortem tooth loss in prehistoric Canary Islanders: Prevalence and contributing factors. International Journal of Osteoarchaeology, 17, 157-173. doi:10.1002/oa.864

[61] Turner, C.G. II, Nichol, C.R. and Scott, G.R. (1991) Scoring procedures for key morphological traits of the permanent dentition: The Arizona State University dental anthropology system. In: Kelley, M.A. and Larsen, C.S., Eds., Advances in Dental Anthropology, Wiley-Liss, New York, 13-31.

[62] Stipcevic, A. (1977) Illyrians. History and Culture. Noyes Press, Park Ridge.

[63] Touminen, M. and Touminen, R. (1991) Tooth surface loss among people exposed to cement and stone dust in the work environment in Tanzania. Community Dental Health, 8, 233.

[64] Bisel, S. (1998) Nutrition in first-century Herculaneum. Anthropology, 26, 61-66.

[65] Messer, L.B. and Cline, J.T. (1980) Ankylosed primary molars: Results and treatment recommendations from an eight-year longitudinal study. Journal of Clinical Pediatric Dentistry, 2, 37-34.

[66] Peck, S., Peck, L. and Kataja, M. (1996) Prevalence of tooth agenesis and peg-shaped maxillary lateral incisor associated with palatally displaced canine (PDC) anomaly. American Journal of Orthodontics and Dentofacial Orthopedics, 110, 441-443. 